\title{
What is the Healthcare Commission trying to achieve?
}

David Haslam

J R Soc Med 2007; 100:15-18

You know that you've heard of the Healthcare Commission, even if you aren't sure who or what it is. Typically described as an independent health watchdog, the Commission always seems to be in the news, usually for publishing headline-grabbing reports about such varied issues as hospital cleanliness, the state of outpatient departments, bullying, or problems with mental health services.

If you are a clinician who is also involved in management, you will inevitably know a great deal more about the Healthcare Commission. You will be aware that in the past the Commission has published star ratings and performance ratings about NHS bodies, and is currently responsible for the Annual Health Check.

But who, or what, is the Healthcare Commission, and what is it trying to achieve? Why does it matter to the average clinician? After all, we all have an apparent alphabet soup of organizations, all of whom seem to be watching our activities. The best known is obviously the GMC, but clinicians in England also may be aware of the NPSA, the NCAS, Monitor and NICE, for a start. Are they all simply quangos of little relevance to everyday practice, or increasingly important parts of medical practice?

\section{FROM CHI TO CHAI}

Almost every working doctor was well aware of the existence of $\mathrm{CHI}$, the Commission for Health Improvement. In April 2004, CHI ceased to function and was replaced by $\mathrm{CHAI}$ - the Commission for Healthcare Audit and Inspection, chaired from the start by Sir Ian Kennedy. Sir Ian was previously the Chairman of the Public Enquiry into children's heart surgery at Bristol Royal Infirmary, published in 2001. The Commission also inherited regulation of the independent sector from the National Care Standards Commission and of 'Value For Money' from the Audit Commission. Right from the start, the phrase 'Commission for Healthcare Audit and Inspection' was deemed to be too much of a mouthful, and whilst this remains the official name of the organization, it is more generally referred to as 'The Healthcare Commission'. Ian Kennedy leads a board of 14 commissioners, appointed

Healthcare Commission, Finsbury Tower, 103-105 Bunhill Row, London EC1Y 8TG, UK

E-mail: David.Haslam@healthcarecommission.org.uk through the Independent NHS Appointments Commission. The Chief Executive of the Commission is Anna Walker, and she heads a team of staff that are based in Bristol, Leeds London, Manchester, Solihull and Nottingham.

The basic functions of the Commission are apparently straightforward:

- To inspect the quality and value for money of health care and public health;

- To equip patients and the public with the best possible information about health care;

- To promote improvements in health care and public health.

Indeed these three keys functions can be summed up in three words: Inspect; Inform; Improve.

In England, the Commission is responsible for assessing and reporting on the performance of NHS and independent health care organizations to ensure that they are providing a high standard of care. It encourages providers to continually improve their services and the way in which they work. Specifically, the Commission's responsibilities include awarding annual performance ratings to NHS organizations, carrying out reviews and investigations of health care, registering and inspecting providers of independent health care, reviewing second stage complaints and reporting annually to Parliament on the state of health care in England and Wales.

Right from the start, the Commission set itself a number of guiding principles, which should underpin its whole way of working:

- A focus on ensuring high quality health care for patients, and ensuring the rights of all to opportunities to improve their health;

- Working in partnership with others, in order to make the burden of regulation and inspection as light as possible;

- Being independent and fair in its decision-making, open and consultative about its decisions, and accountable for its actions.

Most doctors are well aware of, and not a little cynical about, high-minded mission statements produced by health care organizations. However the Healthcare Commission is 
genuinely committed to ensuring that these aspirations are the basis of its work, and will inevitably be judged on this.

\section{PATIENTS FIRST}

When the Commission was set up its vision was to place patients at the heart of everything it does. It committed itself to measuring those aspects of care and performance that matter to patients, as well as those that matter to the clinicians and others responsible for providing health care services. It was also clear early on that the burden of regulation, and in particular multiple inspection visits, caused real disruption to the NHS. To address this, the Commission led the development of the Concordat - an agreement between 20 bodies involved in the regulation of health care in England, in which information and inspection is intended to be shared and duplication avoided. I will discuss this in more detail later.

In addition, the Commission has started to bring together the regulation of independent health care providers and NHS trusts, and worked towards setting the same high requirements for both sectors. The Commission also established a new system for handling complaints about the NHS that cannot be resolved locally and put in place the building blocks of the system designed to ensure that they could work locally.

In April 2005, the Commission unveiled a radical new approach to assessing and reporting on the performance of health care organizations, called the annual health check. A major step away from the old system of star ratings, the annual health check aims to provide a much richer picture of performance than ever before and aims to offer real insight into the experiences of patients across health care services. The new system emphasizes improvement and better outcomes in health and health care, and uses information to ensure a targeted and proportionate approach to assessment. The new system is designed to be more cost-effective and steps are being taken to align assessments of health care across the NHS and independent sector. The first assessment, for the year ending $31 \mathrm{March}$ 2006, was published in October 2006.

\section{CLINICAL ASPECTS OF THE HEALTHCARE COM- MISSION'S WORK}

\section{Clinical audit}

Clinical audit measures the care given by clinicians to individual patients against good practice guidance and identifies when and if they can do better. Information about outcomes (e.g. survival after major surgery), when properly adjusted for differences in 'case mix' (how ill patients are when they receive care, how old they are, etc.), provides direct information about what happens to the health of the done locally, it is most powerful when carried out nationally so that a benchmark can be derived and clinicians can assess their practice against that standard. In the UK the largest support for national audit (National Clinical Audit \& Patients' Outcomes Programme) comes from the Healthcare Commission. The Programme for 2005/2006 includes 27 projects at varying stages of development, with a total budget of about $£ 5$ million.

These audits serve several and various purposes. Some are important for surveillance, so that colleagues, clinical and medical directors, SHA performance leads and colleagues in the Department of Health and the Healthcare Commission can be assured that the care given accords with acceptable standards. Because more accurate expectations from various treatments can be disseminated, this activity can be genuinely informative for patients and can be used to improve discussion around consent and support the 'choice' agenda. The Commission has also worked with the Society of Cardiothoracic Surgeons to develop a web-based link to information on adult heart surgery so that patients and relatives can easily access this information in a form that they find useable (http://heartsurgery.healthcarecommission.org.uk).

The programme includes audits of cancer treatment, including bowel, lung, head and neck and oesophagogastric cancers. Other audits include aspects of diabetes, violence in mental health, strokes and carotid endarterectomy and incontinence, amongst others. Many of the audits relate to heart disease, such as adult and paediatric heart surgery, coronary intervention, heart rhythm management, and the myocardial infarction national audit programme (MINAP). The Central Cardiac Audit Database (CCAD) holds these latter audits for the Commission, which is part of the National Clinical Audit Support Programme (NCASP) under the umbrella of the NHS Information Centre. The CCAD links with the Office of National Statistics (ONS) for patient mortality tracking and NHS number retrieval, and integrates these several audits together so that colleagues can access late mortality and additional intervention following one of these procedures. The Commission hopes to initiate additional audits and several have gone through a scoping exercise.

Yet there is more to be done. Many more requests to carry out national audits are received than the Commission has the resources to carry out. In addition, the current programme is being refined and modernized to ensure that they are multidisciplinary with possible links into primary care.

\section{Clinical engagement}

In the past there have been concerns that clinicians practising in the NHS or working closely with the NHS 
were not always aware of, or involved in, the targets and indicators that were used to manage and assess performance of NHS organizations. This was despite widespread clinical support for many central initiatives, such as national service frameworks. It has also been suggested that some of the existing measures of performance were not sufficiently relevant to the work of clinicians or the patients they were treating. In response to this the 'better metrics' project was established in January 2004. The aim of the project is to develop better measures of performance, which have greater relevance to the work of clinicians and can be used to support the development of local targets and other indicators of quality. The project was transferred to the Healthcare Commission in April 2005, from the Office of the Strategic Health Authorities, and already contributes to work being carried out across the Commission, including using metrics as part of the screening process for the annual health check.

It is also vital to note that the Department of Health, not the Healthcare Commission, sets the actual standards on which the NHS is assessed. In July 2004, the Department of Health published National Standards, Local Action: Health and Social Care Standards and Planning Framework 2005/ 2006-2007/2008, setting out 24 essential or 'core' standards that NHS organizations in England should be achieving and 13 developmental standards that they should be aiming to achieve in the future. The framework also included fewer national targets, with the expectation that primary care trusts will use this opportunity to set more local targets. Within this new system, it is expected that better metrics will improve the relevance of measures of performance for clinicians, help to align local initiatives with the aim of improving the quality of services, and encourage overlap between measures in difference aspects of the framework. It is also expected that it will allow performance to be benchmarked and provide, potentially, 'expert' support to organizations in developing measurable local targets and indicators of quality.

Better metrics have already been suggested for 13 key health areas, including cancer, heart disease, stroke, mental health and learning disabilities. The better metrics project is a work in progress, and the Commission expects the scope of the project to grow and change in response to changes in health care, such as the introduction of new national service frameworks. The Commission wants to encourage clinicians to give feedback and input into the system that assesses the NHS.

There are a number of ways for clinicians to become involved with the work of the Healthcare Commission. Further information about these, the clinicians' e-bulletin and other programmes of work can be found on the Healthcare Commission website at www.healthcarecommission.org.uk.

\section{THE ANNUAL HEALTH CHECK}

In the past couple of years, the Commission has completed a comprehensive agenda of activity, but the challenges continue. Within the NHS there will be continuing system reform, such as payment by results and patient choice, and major structural change. The financial pressures on the service are also likely to intensify. As every doctor is aware, the health care industry is far from stagnating and in a changing and dynamic environment everyone can expect to see greater plurality, with the independent sector organizations inevitably taking an increasing array of services. In April 2006, the Secretary of State asked the Commission to review the quality of care provided by Independent Sector Treatment Centres. The Commission also recognizes that it is taking the first steps in a huge process of change. While some projects are already under way, others, such as programmes to promote improvement, have only just begun to take shape.

In light of all the changes taking place in the world of health care and in an effort to drive forward their agenda on promoting improvement, the Healthcare Commission carried out a major consultation on developing the annual health check in 2006/2007. It is committed to ensuring that it assesses and provides information on what matters most to those with an interest in health care, putting patients and the public at the heart of this. In the next phase of the annual health check, the Commission will begin to look more at how it can encourage trusts to improve their performance beyond key targets and core standards. It will look even more closely at whether NHS organizations are 'making and sustaining progress' and will continue to carry out a number of reviews focusing on the services to particular groups of patients provided across different organizations. The Commission expects that over the next few years this more flexible, less organization-focused system of assessment, which emphasizes assessing 'pathways of care', will become increasingly important.

In the first year, the annual health check focused on making sure basic standards are met by the NHS. A key development for 2006/2007 would be the possible introduction of assessment against some aspects of the developmental standards, which measure improvement. It has consulted on these with a possible view to asking trusts about safety, clinical and cost effectiveness, patient focus and public health. These four areas have been identified because of their importance to the quality of care that patients receive, and to ensure that the health needs of the population are understood and addressed.

The consultation proposed that, in a process similar to the assessment of core standards, trusts would be responsible for assessing their compliance with these standards and making a declaration about performance. 
The Commission has also consulted on plans to conduct focused reviews in priority areas such as diabetes, substance misuse, mental health, race equality and maternity services.

In the past, health care regulation has been hugely burdensome on the NHS, with a number of regulators inspecting at once and multiple organizations asking for the same information. It has long been argued that all this duplication and unnecessary burden took capacity away from where it was needed most - the frontline. In response to this, the Commission was given the role of coordinating the activities of the different bodies involved in reviewing health and health care services, and the annual health check has been developed with this in mind. The Commission wants to ensure that they have as full a picture as possible of how organizations are performing and the annual health check takes account of a wide range of information, some of which is gathered from other regulators and clinical bodies, including the General Medical Council and the Royal College of Physicians.

This commitment to reducing the burden of inspection was the driving force behind the establishment of the Concordat. Launched in June 2004, the Concordat aims to support improvement in health care services, minimize duplication and overlap, ensure that information is shared appropriately, and encourage multidisciplinary reviews and inspections. There are currently 20 signatories working together to coordinate their activities, including audits, reviews and inspections. Further information about the Concordat and its signatories can be found on their website (www.concordat.org.uk), which includes an activity scheduling tool in which you can see exactly what organizations are currently actively involved in inspection or other work with any given trust.

\section{ALIGNING ASSESSMENT OF INDEPENDENT HEALTH CARE AND THE NHS}

The definition of what activity is NHS activity seems to be shifting from 'Who does it?' to 'Who pays for it?'. As a result, the Commission is moving further towards joining up the regulation of NHS and independent health care organizations. The journey of a patient through the health care system is more complex than ever before. Many more patients are receiving care and treatment from a combination of public and independent health care services. The Commission's assessments must assure that standards are met at all stages of this journey. In 2005/2006, the Commission introduced the annual health check-an entirely new system for assessing the NHS - and started to make independent sector inspections more risk based, within annual visits. Now they have set about further modernizing the way they regulate health care in the independent sector so as to align it with the NHS assessment of core standards and other elements of the annual health check.

The Commission also recently consulted on their broad aims and proposals relating to alignment, which were designed to create a framework to aid progress towards a single system of assessment. Change needs to be brought in at a manageable pace, ensuring that learning takes place in both the independent sector and in the NHS as the annual health check develops. More detailed information about how the new systems will develop and be implemented in 2006/2007 and beyond will published in due course.

\section{THE FUTURE OF HEALTH AND SOCIAL CARE REGULATION}

As if all this complexity and activity weren't enough, in March 2005, Chancellor Gordon Brown announced in his budget statement a plan to merge the health and social care inspectorates. The proposed merger recognizes that patients move continually between health and social care and gives health services a modern and efficient regulatory system.

The Department of Health's recently published white paper Our Health, Our Care, Our Say: A New Direction for Community Services (January 2006) confirmed the Government's intention to merge the Healthcare Commission and Commission for Social Care Inspection within the context of a wider review of regulation. The Department of Health has also confirmed that the Healthcare Commission and the Mental Health Act Commission will merge. The Commission already works closely with the Commission for Social Care Inspection and the Mental Health Act Commission, and will continue to do so throughout 2006/2007, but the details of merger are obviously complex and have not yet been finalized.

As the Commission moves into its third year in operation it will focus on three key objectives - ensuring the basics are in place, encouraging improvement and making information more accessible - whilst ensuring that the interests and concerns of patients and the public are at the forefront. Bringing together the regulation of health and social care will offer its own unique challenge.

As Mark Twain once said, 'I'm all for progress. It's change I can't stand'. Those of us who work in health care often know the frustration and irritation that lay behind this remark, which is why the Commission is determined to engage with and listen to clinicians.

After all, our personal and corporate aspirations are remarkably similar. Quality really does matter. 